\title{
Images in ophthalmia nodosa: an unusual presentation of red eye
}

\author{
Nicholas David St John Savage, ${ }^{1}$ Jessica Catherine Philippa Green, ${ }^{2}$ Fiona Carley ${ }^{3}$
}

'Ophthalmology, Shrewsbury and Telford Hospital NHS Trust, Shrewsbury, Shropshire, UK ${ }^{2}$ Stroke Medicine, Wye Valley NHS Trust, Hereford, Herefordshire, UK

${ }^{3}$ Ophthalmology, Manchester Royal Eye Hospital, Manchester, Greater Manchester, UK

\section{Correspondence to} Dr Nicholas David St John Savage,

nicksavage@doctors.org.uk

Accepted 20 February 2018

\section{DESCRIPTION}

Caterpillars, tarantulas and vegetation produce a variety of defence fibres (called setae) uniquely adapted to penetrate the tissues of their target. ${ }^{1}$ Ophthalmia nodosa $(\mathrm{ON})$ is an ocular inflammatory reaction resulting from these setae entering the eye. Microscopic barbs on the surface of setae facilitate their entry into the cornea with subsequent migration to underlying structures leading to potentially sight-threatening conditions such as vitritis and endophthalmitis. ${ }^{2}$

A 41-year-old man presented to Manchester Royal Eye Hospital with a 6-day history of unilateral left-sided red eye and pain secondary to a caterpillar falling into his eye while on an adventure holiday (figure 1). Prior to presenting in the UK, he had sought initial medical attention in the USA, where multiple foreign bodies were noted. He was treated with chloramphenicol eye ointment, and no follow-up was arranged.

On re-presentation in the UK, slit-lamp examination revealed setae embedded within his conjunctiva and eyelids causing multiple corneal abrasions. There was no evidence of intraocular inflammation. Optic disc and macula were normal. Visual acuity was $6 / 6$ in both eyes.

The patient was taken to theatre to remove as many setae as possible. Single-use suture-tying forceps were used, including for those setae in the conjunctiva, cornea and subtarsal surfaces. Subsequent surgery (with anaesthesia) allowed more deeply embedded setae to be removed, particularly within the conjunctiva. Interestingly, very few setae initially affected the cornea. Removal was always attempted in the direction of barbs, but this was complicated because some barbs were friable and liable to break if pulled too hard.

Postoperatively, he was prescribed both ofloxacin and prednisolone $(0.5 \%)$ eye-drops four times a

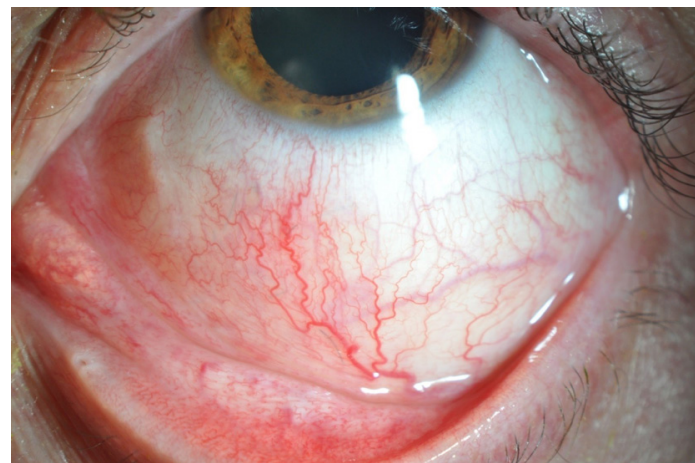

Figure 1 Acute red eye and visible seta on cornea.

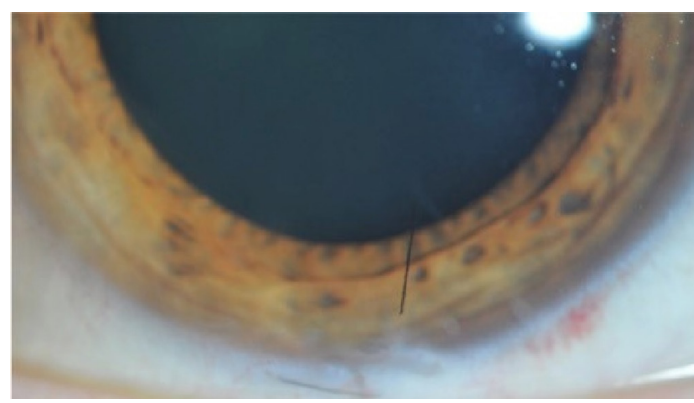

Figure 2 Seta within deep cornea.

day. To alleviate the pain from his abrasions, he was given Viscotears and cyclopentolate 1\% two times per day. A plan was made for follow-up at 2 weeks. On this occasion, further setae were identified and removed.

Despite regular follow-up, the patient re-presented with ocular pain while running. Unexpectedly, slit-lamp examination revealed a single seta in the deep cornea threatening his visual axis which had not been evident previously (figure 2). Visual acuity was unaffected. Given the patient had no visual loss, it was decided that the risks of corneal surgery to remove a single seta outweighed the benefits. A conservative approach was adopted. His topical steroids were restarted with the addition of loteprednol to manage his steroid response.

At review 1 month later, it was noted that the seta had migrated further into the centre of the cornea so he was kept under review (figure 3). At 9 months, he presented with acute ocular pain. Examination revealed that the seta had migrated to the surface of the cornea and penetrated through the epithelium (figure 4). Even so, the damage to the epithelium

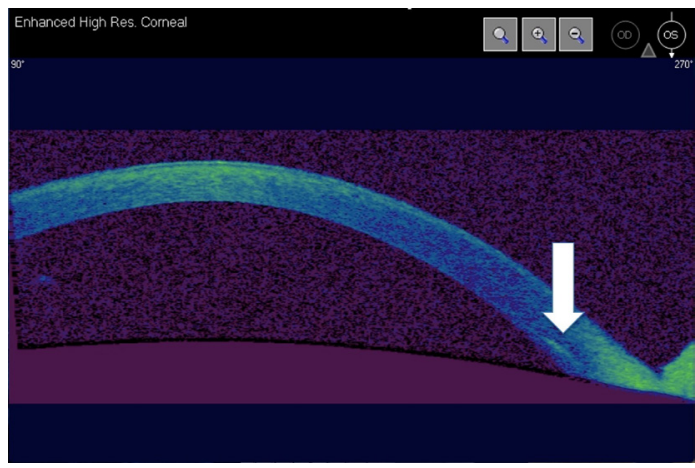

Figure 3 OCT image showing single seta (deep seated) in bottom right-hand corner 


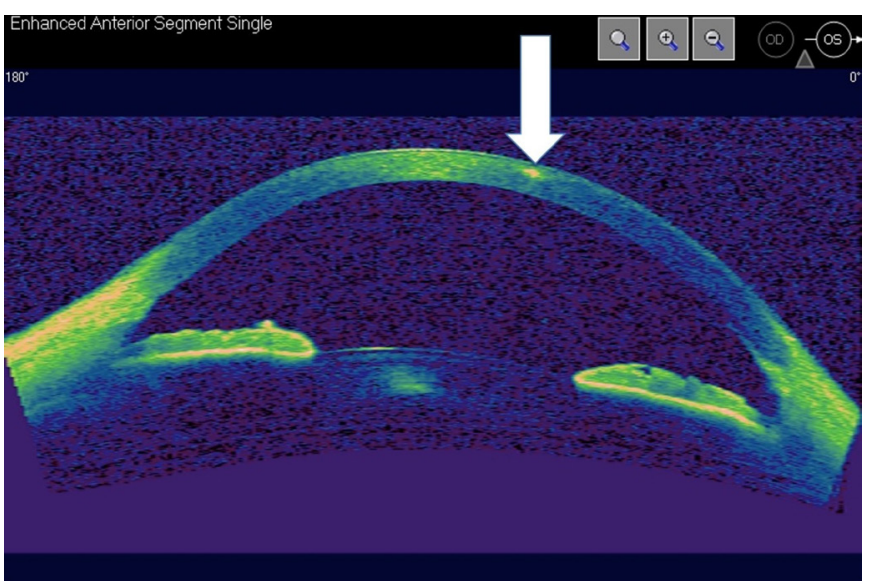

Figure 4 OCT image showing seta having migrated anteriorly.

and stroma was minimal, and the entire seta was subsequently removed without complication with forceps.

\section{Patient's perspective}

I was on an adventure holiday when the caterpillar fell in my eye, it was pretty nasty. I thought the doctors in the States had sorted it, but the pain didn't go away and in fact it got worse. I had to go to hospital in the UK and was amazed that the caterpillar spines were in my eyeball! It was weird when I developed pain again while out running. I was relieved that the caterpillar worked its way out in the end. Painful though it was, it was great to hear that my experience will go some way to helping the next rare unfortunate who has the same predicament.

\section{Learning points}

Red eye can be inflammatory as well as infective. This case and its images show how persistent red eye can be unresolved inflammation masquerading as infection.

- The importance of scrupulous removal of setae in ophthalmia nodosa.

- Long-term follow-up recommended due to late presentation of retained migrating setae.
Although it was theoretically possible that the seta which occurred at a later stage may have been hidden sub-tarsally, this is believed to be unlikely as the seta had been initially deeply embedded in the conjunctiva, before migrating to the sclera and finally to the cornea. A subtarsal sweep for any remaining setae is advisable and, therefore, the subtarsal plate should always be examined.

Setae can migrate due to their own unique properties of propulsion. ${ }^{2}$ The images demonstrate how close the seta came to penetrating the anterior chamber. The trajectory of the seta appeared to change (figure 4), and this has not been previously reported in the literature. This case demonstrates that despite removing all seta visible at the time, late presentations of progressively migrating seta can occur. Setae can remain in the globe and form granulomas which tend to require surgical excision or penetrate the posterior segment and cause vitritis and endophthalmitis. ${ }^{2}$ All patients should be warned of this possibility and encouraged to attend follow up clinics.

Misdiagnosis with ocular infection can delay appropriate treatment for ON. Early identification and removal of setae are key to prevention of lasting corneal injury. Wherever possible, all setae should be removed. ${ }^{3}$ This significantly reduces the risk of vitreoretinal involvement. This may require more than one surgical procedure. ${ }^{4}$

To control the associated inflammation, topical steroids are required with regular follow-up, and pressure monitoring is advised for all patients.

Contributors NDSJS: report compilation. JCPG literature review. FC: images, proofreading.

Funding The authors have not declared a specific grant for this research from any funding agency in the public, commercial or not-for-profit sectors.

Competing interests None declared.

\section{Patient consent Obtained.}

Provenance and peer review Not commissioned; externally peer reviewed.

(c) BMJ Publishing Group Ltd (unless otherwise stated in the text of the article) 2018. All rights reserved. No commercial use is permitted unless otherwise expressly granted.

\section{REFERENCES}

1 McAnena L, Murphy C, O'Connor J. "Tarantula Keratitis" a case report. Ir J Med SC 2013;182:349-50.

2 Steele C, Lucas DR, Ridgway AE. Endophthalmitis due to caterpillar setae: surgical removal and electron microscopic appearances of the setae. $\mathrm{Br} J$ Ophthalmol 1984;68:284-8.

3 Sengupta S, Reddy PR, Gyatsho J, et al. Risk factors for intraocular penetration of caterpillar hair in ophthalmia nodosa: a retrospective analysis. Indian J Ophthalmol 2010;58:540-3

4 Doshi PY, Usgaonkar U, Kamat P. A hairy affair: ophthalmia nodosa due to caterpillar hairs. Ocul Immunol Inflamm 2018;26:136-41.

Copyright 2018 BMJ Publishing Group. All rights reserved. For permission to reuse any of this content visit

http://group.bmj.com/group/rights-licensing/permissions.

BMJ Case Report Fellows may re-use this article for personal use and teaching without any further permission.

Become a Fellow of BMJ Case Reports today and you can:

- Submit as many cases as you like

- Enjoy fast sympathetic peer review and rapid publication of accepted articles

- Access all the published articles

- Re-use any of the published material for personal use and teaching without further permission

For information on Institutional Fellowships contact consortiasales@bmjgroup.com

Visit casereports.bmj.com for more articles like this and to become a Fellow 